\title{
In Situ Matrix Volatilization for Trace Element Determination in High Purity Antimony and Antimony Oxide and Elucidation of the Atomization Mechanisms by ETAAS
}

\author{
Suvarna Sounderajan, G. Kiran Kumar, A.C. Udas*, and T. Mukherjee \\ Analytical Chemistry Division, Bhabha Atomic Research Centre, Trombay, Mumbai-400 085, India
}

\begin{abstract}
A method is described for the trace level determination of $\mathrm{Ag}$, $\mathrm{Cd}, \mathrm{Co}, \mathrm{Cu}, \mathrm{Cr}, \mathrm{Fe}, \mathrm{Mn}$, and $\mathrm{Ni}$ in high purity (HP) antimony employing in situ removal of the matrix using electrothermal atomic absorption spectrometry (ETAAS) under STPF conditions. The effect of the pre-atomization and atomization temperature on the analyte signal in the sample digest containing varying concentrations of the matrix has been studied, and the furnace temperatures were optimized to obtain matrix-free analyte peaks. The recoveries of spiked impurities under optimized conditions were found to be greater than $90 \%$. The collective detection limit of the elements studied was less than $2.0 \mu \mathrm{g} \mathrm{g}^{-1}$ and varied from $0.01 \mu \mathrm{g} \mathrm{g}^{-1}$ for Cd to 1. $3 \mu \mathrm{g} \mathrm{g}^{-1}$ for Fe. Validation of the procedure was carried out by ex-situ volatilization of the matrix as bromide and determination of the analytes in the residue. This method offers low blanks, permits the use of up to $25 \mathrm{mg} \mathrm{mL}^{-1} \mathrm{Sb}$, and has been applied for the determination of trace impurities in $\mathrm{Sb}$ and $\mathrm{Sb}_{2} \mathrm{O}_{3}$ samples of $99.99 \%(4 \mathrm{~N})$ to $99.999 \%(5 N)$ purity.
\end{abstract}

\section{INTRODUCTION}

High purity (HP) antimony is important and used as a dopant in III-V semi-conductor material in the manufacture of IR detectors, diodes, and hall-effect devices. Electrical properties of these devices are

* Corresponding author.

E-mail:acudas@barc.gov.in
The reaction mechanism leading to the formation of free analyte atoms in the aqueous, as well as the $\mathrm{Sb}$ matrix was studied. It was seen that in the aqueous matrix, $\mathrm{Co}$ and $\mathrm{Cu}$ undergo carbothermic reduction of the oxide, followed by atomization of the $\mathrm{M}_{(\mathrm{s})}$ to $\mathrm{M}_{(\mathrm{g})}$. Two activation energies were obtained, one corresponding to the atomization of the metal atom $\mathrm{M}_{(\mathrm{s})} \rightarrow \mathrm{M}_{(\mathrm{g})}$ and the second to the dissociation of the dimer $\left(\mathrm{M}_{2(\mathrm{~g})}\right)$. However, there was no indication of dimer formation in the $\mathrm{Sb}$ matrix. The atomization mechanisms of all other analytes with and without matrices remained the same.

Based on these investigations, an analytical methodology was developed which involves dissolution of high purity $\mathrm{Sb} / \mathrm{Sb}_{2} \mathrm{O}_{3}$ in aqua regia, stabilized with $5 \%$ recrystalized tartaric acid and employing optimized furnace temperatures to obtain interference-free signals of the analytes. It is of significance to note that the present method gains in importance for its ability to determine all of these analytes without the need for a prior chemical separation of the matrices.

affected by the concentration and nature of the impurities present in the material (1). Therefore, accurate characterization of the trace elemental impurities in high purity material is of critical importance.

Instrumental techniques with low detection limits that employ solid sampling, such as glow discharge quadrupole mass spectrometry (GD-QMS) and laser or spark ablation inductively coupled plasma mass spectrometry (LA, SPICP-MS), are the preferred methods (2-5) for the estimation of trace impurities in HP materials. However, the high cost of GDMS, the lack of suitable reference samples for different matrices, and the need to establish the relative sputtering factor (RSF) have greatly restricted their applicability. In addition, analytical results which depend on homogeneity, quality and surface states of the solid samples suffer from large variations when quantification of impurities in real samples carried out by LA or SP-ICP-MS.

When low concentrations of trace impurities are to be determined, the conventional techniques of inductively coupled plasma optical emission spectrometry (ICPOES), ICP-MS, and other mass spectrometric methods have limitations due to the spectral interference of the matrix and intolerance effects due to mass. Therefore, chemical processing of samples employing preconcentration procedures (6) based on matrix-analyte separation is considered. Since detection limits are largely limited by the blank, minimum sample processing carried out in a controlled environment and using high purity reagents and element-specific chemistry is a possible alternative to direct solid sampling.

Methodologies employing separation techniques, such as ion exchange and vapor phase removal of antimony, coupled with sensitive detection techniques of ICP-QMS, ICP-OES, or ETAAS for the determination of trace impurities in the residue, have been reported (7-11). 
However, these procedures are time-consuming and prone to contamination.

A technique is required that offers in situ matrix removal and subsequent estimation of the analyte could overcome matrix contamination related difficulties. ETAAS is a selective, sensitive, low cost technique, reasonably free from spectral interferences, and offers the possibility of in situ removal of the matrix by employing appropriate pre-atomization and atomization temperatures. The relatively long residence times and efficient sample delivery are such that the absolute limits of detection can surpass those of ICP-MS (12). Estimation of trace elements in HP copper (13), arsenic (14), zirconium (15), and indium in HPSb (16) employing in situ matrix volatilization ETAAS has been reported. Direct solid sampling GFAAS for the determination of trace elements in the refractory materials of HP tungsten, boron nitride, and aluminum nitride (17-20), etc., has also been reported.

An attempt has been made to understand the atom formation mechanism of individual analytes in the presence and absence of the matrix from signal appearance temperature, Arrhenius plots and activation energy calculations and correlation of these data with the thermodynamic data that have been reported (24,28).

In this study, we present a simple method employing the in situ removal of antimony for the determination of non-volatile trace element impurities in high purity antimony (HPSb), and antimony oxide $\left(\mathrm{HPSb}_{2} \mathrm{O}_{3}\right)$ under STPF conditions using GFAAS, equipped with deuterium lamp background correction. It involves dissolution of $\mathrm{HPSb}$ and $\mathrm{HPSb}_{2} \mathrm{O}_{3}$ in a minimum amount of aqua regia and stabilizing it with 5\% recrystalized tartaric acid. The effect of the antimony matrix on the analyte signals has been studied and $\mathrm{Ag}, \mathrm{Cd}, \mathrm{Co}, \mathrm{Cu}$, $\mathrm{Cr}, \mathrm{Fe}, \mathrm{Mn}$, and $\mathrm{Ni}$ were quantified using optimized furnace temperatures. It has been applied for the determination of impurities in $\mathrm{Sb}$ samples of 99.99 and $99.999 \%(5 \mathrm{~N})$ purity. This procedure permits the use of an antimony solution up to $25 \mathrm{mg} \mathrm{mL}^{-1}$, offers low experimental blanks and low method detection limits. All operations were carried out in a clean room environment. In the absence of certified reference material, the per- formance of this method was evaluated by analyzing synthetic samples. The standard addition and recovery values obtained in the samples were found to be between 95-104\%. Validation of the results was carried out by volatilization of the matrix as bromide and determination of the analytes in the residue.

\section{EXPERIMENTAL}

\section{Instrumentation}

All measurements were carried out on a Model GBC 906 AA, equipped with pyrolytically coated graphite platform furnace tubes. All measurements were performed using integrated absorbance (peak area). Elemental hollow cathode lamps of $\mathrm{Ag}, \mathrm{Cd}, \mathrm{Co}, \mathrm{Cr}, \mathrm{Cu}, \mathrm{Fe}, \mathrm{Mn}$ and Ni (GBC, Australia) were used. The instrumental operating conditions for the trace element determinations are listed in Table I.

A CEM MDS-2100 (NC, USA) microwave sample preparation system was used for sample dissolution. The dissolutions were carried out in CEM Advanced Composite Vessels capable of withstanding pressures up to $600 \mathrm{psi}$.

TABLE I

FAAS Instrumental Parameters for the Determination of Trace Elements

\begin{tabular}{|c|c|c|c|c|c|c|c|c|}
\hline Elements & $\mathrm{Ag}$ & $\mathrm{Cd}$ & Co & $\mathrm{Cr}$ & $\mathrm{Cu}$ & $\mathrm{Fe}$ & $\mathrm{Mn}$ & $\mathrm{Ni}$ \\
\hline Drying temp $\left({ }^{\circ} \mathrm{C}\right)$ & 120 & 120 & 120 & 120 & 120 & 120 & 120 & 120 \\
\hline Ramp time (s) & 5 & 5 & 5 & 5 & 5 & 5 & 5 & 5 \\
\hline Hold time (s) & 5 & 5 & 5 & 5 & 5 & 5 & 5 & 5 \\
\hline Pyrolysis temp $\left({ }^{\circ} \mathrm{C}\right)$ & 400 & 300 & $400 / 800$ & $600 / 1100$ & $600 / 800$ & $600 / 800$ & $500 / 700$ & $600 / 900$ \\
\hline Ramp time (s) & 5 & 5 & $5 / 5$ & $5 / 5$ & $5 / 5$ & $5 / 5$ & $5 / 5$ & $5 / 5$ \\
\hline Hold time (s) & 5 & 50 & $5 / 5$ & $5 / 5$ & $5 / 5$ & $5 / 5$ & $5 / 5$ & $5 / 5$ \\
\hline Atomization temp $\left({ }^{\circ} \mathrm{C}\right)$ & 2000 & 2000 & 2300 & 2500 & 2300 & 2300 & 2300 & 2400 \\
\hline Cleaning temp $\left({ }^{\circ} \mathrm{C}\right)$ & 2100 & 2100 & 2400 & 2600 & 2400 & 2400 & 2400 & 2500 \\
\hline Wavelength (nm) & 328 & 228.8 & 240.7 & 357.90 & 324.7 & 248.3 & 279.5 & 232.0 \\
\hline Slit width (nm) & 0.5 & 0.5 & 0.2 & 0.2 & 0.5 & 0.2 & 0.2 & 0.2 \\
\hline Read time (s) & 3 & 3 & 3 & 3 & 3 & 3 & 3 & 3 \\
\hline
\end{tabular}

All measurements were carried out using pyrolytically coated graphite tubes and absorbance was measured in peak area mode. 


\section{Reagents and Standard Solutions}

Antimony oxide (Johnson \& Mathey, UK) of greater than $5 \mathrm{~N}$ purity was used in this study. Suprapur ${ }^{\circledR}$ nitric acid (65\%) and Suprapur ${ }^{\circledR}$ hydrochloric acid (35\%) (E. Merck, Darmstadt, Germany) were used for all sample treatments. Nanopure ${ }^{\circledR}$ water with a resistance of $18.3 \mathrm{M}-\Omega$, obtained with a Barnstead Thermolyne water purification system (Barnstead, Dubuque, IA, USA), was used for all dilutions and rinsings.

Standard solutions of Ag, Cd, $\mathrm{Co}, \mathrm{Cu}, \mathrm{Cr}, \mathrm{Fe}, \mathrm{Mn}$, and Ni were prepared by sequential dilution of certified AAS standard solutions (1 $\mathrm{mg} \mathrm{mL}^{-1}$ ) (E. Merck). Tartaric acid was purified by fractional crystallization of A.R. grade tartaric acid (E. Merck), and 5\% tartaric acid was prepared from fractionally recrystalized tartaric acid.

The containers and glassware were cleaned by soaking them successively in three baths of $10 \%, 1 \%$, and $0.1 \%$ doubly distilled nitric acid in Nanopure water. All glassware was stored in $0.1 \%$ nitric acid baths until further use.

\section{Analytical Procedure \\ Sample Dissolution}

The vessels were initially cleaned by thoroughly rinsing with Nanopure water. Then $5 \mathrm{~mL}$ of Suprapur $\mathrm{HNO}_{3}$ was added, the vessels placed in the microwave digestion system, and subjected to a clean cycle. The vessels were cooled, the contents discarded, and rinsed with Nanopure water. Accurately weighed $0.5 \mathrm{~g}$ of antimony or a $0.5 \mathrm{~g}$ antimony equivalent of antimony oxide sample was transferred to the vessels. To check the recoveries of the impurities, a multi-element standard solution containing analyte impurities at two concentrations along with $0.5 \mathrm{~g}$ antimony equivalent to antimony oxide were transferred into cleaned vessels.
Then $3.75 \mathrm{~mL}$ concentrated hydrochloric acid and $1.25 \mathrm{~mL}$ nitric acid were added to all the vessels. Sample blanks were prepared by running aliquots of $3.75 \mathrm{~mL}$ $\mathrm{HCl}+1.25 \mathrm{~mL} \mathrm{HNO}_{3}$ in empty vessels along with the samples.

The samples were digested using the following program:

$\begin{array}{lcc} & \text { Stage I } & \text { Stage II } \\ \text { Microwave power } & 70 \% & 80 \% \\ \text { Time } & 5 \mathrm{~min} & 10 \mathrm{~min} \\ \text { Maximum Pressure } & 75 \mathrm{psi} & 100 \mathrm{psi}\end{array}$

The vessels were cooled, diluted with 5\% recrystallized tartaric acid, and transferred to a $10-\mathrm{mL}$ volumetric flask resulting in a $50 \mathrm{mg} \mathrm{mL}^{-1}$ Sb solution.

\section{Bromide Volatilization $(10,11)$}

Antimony samples, Sb-Ia and Sb-Ib of $0.1 \mathrm{~g}$, were transferred to a quartz beaker, $3 \mathrm{~mL}$ aqua regia was added, and the solution heated on a ceramic top hot plate until the sample dissolved. Then $2 \mathrm{~mL}$ of $\mathrm{H}_{2} \mathrm{SO}_{4}$ was added and the sample digest heated until sulfuric acid fumes appeared. A $2 \mathrm{~mL}$ amount of $\mathrm{HBr}$ was added to the sample digest and heated until the matrix was completely volatilized. Finally, $2 \mathrm{~mL}$ of $\mathrm{HNO}_{3}$ was added to remove excess $\mathrm{HBr}$ and the residue made up to $5 \mathrm{~mL}$ volume with $5 \% \mathrm{HNO}_{3}$. The sample blanks were prepared by volatilizing the acids using the above procedure. All samples were processed in a Class 100 LAF bench.

\section{Standard and Sample Solutions}

A series of aqueous standard solutions of the analytes investigated were prepared in the required concentration range from the $50 \mathrm{mg} \mathrm{mL}^{-1}$ stock solutions. Another set of solutions was prepared with fixed analyte concentrations, but by varying the $\mathrm{Sb}$ matrix concentration (0 to $25 \mathrm{mg} \mathrm{mL}^{-1}$ ) for all of the analytes investigated. A series of standards of $\mathrm{Ag}, \mathrm{Cd}, \mathrm{Co}, \mathrm{Cr}, \mathrm{Cu}$, $\mathrm{Fe}, \mathrm{Mn}$, and Ni were prepared in $25 \mathrm{mg} \mathrm{mL}^{-1} \mathrm{Sb}$.

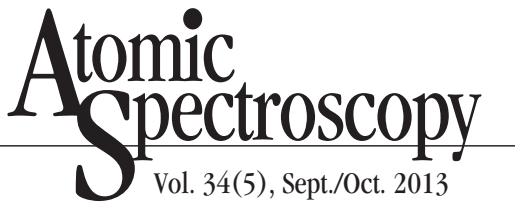

The spiked samples were made up to $25 \mathrm{mg} \mathrm{mL}^{-1} \mathrm{Sb}$ solutions with the analytes at two different concentration levels ( $2 \mathrm{ng}$ to $100 \mathrm{ng} \mathrm{mL}^{-1}$ ).

\section{Optimization of Furnace Condi- tions and Effect of Matrix}

The pre-atomization and atomization temperatures of the individual analytes in aqueous standard solutions were optimized under STPF conditions to obtain a sharp, stable peak with an optimum analyte signal-to-noise ratio. The effects of the pyrolysis temperatures from $300{ }^{\circ} \mathrm{C}$ to $1200{ }^{\circ} \mathrm{C}$ and the atomization temperatures from $1800{ }^{\circ} \mathrm{C}$ to $2600{ }^{\circ} \mathrm{C}$ on the absorbance of the different analytes were studied. Optimized temperatures were used to estimate the absorbance of a fixed concentration of analyte by varying the concentrations of the matrix (0 to $25 \mathrm{mg} \mathrm{mL}^{-1} \mathrm{Sb}$ ). The optimum matrix concentration that gave a reproducible and measurable analytical signal was used to carry out the analyses (Figure 1, Table II). The effect of the matrix was estimated by comparing the slope of the calibration curves and the characteristic concentrations obtained using the absorbance of the analytes in the aqueous and matrixspiked solutions. The individual analyte LOD and LOQ was estimated from seven replicates of the blanks prepared with the aqueous and the $\mathrm{Sb}$ matrix.

\section{Determination of Atomization Mechanism of the Analytes by Determining the Activation Energy $\left(E_{a}\right)$}

The atomization mechanism was studied using the absorbance-timetemperature curve of the analytes. The lowest temperature, where a detectable signal was obtained above the blank signal, was taken as the appearance temperature $\left(\mathrm{T}_{\mathrm{app}}\right)$ of the analyte in the aqueous matrix and the $\mathrm{Sb}$ matrix. At a range of closely spaced points from $\mathrm{T}_{\mathrm{app}}$ 
on the temperature axis, the corresponding absorbances were measured. The Arrhenius plot of logarithm absorbance as a function of inverse absolute temperature was obtained and used to calculate the activation energy $\left(\mathrm{E}_{\mathrm{a}}\right)$. The $\mathrm{E}_{\mathrm{a}}$ of the analytes in the aqueous and the $\mathrm{Sb}$ matrix were compared with the thermodynamic data from the literature $(24,28)$.

\section{Determination of Trace Impurities of $\mathrm{Ag}, \mathrm{Cd}, \mathrm{Cu}, \mathrm{Co}$, Cr, Fe, Mn, and Ni}

The required amounts of processed samples, spiked samples, blanks, and aqueous standards were injected into the graphite furnace using the auto-mix function of the autosampler. The analytes were estimated sequentially under STPF conditions using the optimized temperature program.

\section{RESULTS AND DISCUSSION}

\section{Sample Dissolution}

Antimony is a ubiquitous element which dissolves in oxidizing acids like aqua regia to the form of $\mathrm{SbCl}_{3}$ (see Eq. 1). $\mathrm{SbCl}_{3}$ hydrolyzes at low acid concentrations and separates to form oxoantimonyl compounds such as $\mathrm{SbOCl}$ (see Eq. 2). Since high acid concentrations reduce the life of the graphite furnace, the aqua regia sample digest was stabilized with tartaric acid, which solubilizes SbOCl to form the complex hydrogen antimony tartarate and decomposes around $200{ }^{\circ} \mathrm{C}$ (see Eq. 3).

$$
\begin{gathered}
(\mathrm{Eq} .1) \\
\mathrm{Sb}+\mathrm{HNO}_{3}+3 \mathrm{HCl} \Rightarrow \mathrm{Sb}^{+3}+3 \mathrm{Cl}^{-}+\mathrm{NO} \Uparrow^{2}+2 \mathrm{H}_{2} \mathrm{O} \\
\mathrm{Sb}^{3}+\mathrm{Cl}^{-}+\mathrm{H}_{2} \mathrm{O} \Rightarrow \mathrm{SbOCl}+2 \mathrm{H}^{+}
\end{gathered}
$$

$\mathrm{SbOCl}+\mathrm{HOOC}-\mathrm{CH}(\mathrm{OH})-\mathrm{CH}(\mathrm{OH})-\mathrm{COOH} \Rightarrow$ [OOC-CH$(\mathrm{OH})-\mathrm{CH}(\mathrm{OH})-\mathrm{COOSbO}]^{-}+2 \mathrm{H}^{+}+\mathrm{Cl}^{-}$

The impurities in tartaric acid contribute to the blank value and degrade the detection limits (22) and, therefore, was purified by recrystallization.

\section{Optimization of GF Temperature Program and Effect of Matrix}

Free atoms are formed either due to disassociation of the oxide or due to carbothermic reduction of the oxide. The presence of a matrix greatly affects the atomization of the analyte in the graphite furnace (GF) and the final result is the combined effect of analytematrix, analyte-carbon, and carbonmatrix interactions. Therefore, the atomization behavior of the analytes was studied both in the presence and in the absence of the matrix prior to optimization of the method. In situ volatilization of the matrix requires effective optimization of the furnace conditions to overcome the matrix effects and to ensure sharp reproducible peaks with an optimum signal-to-noise ratio. In the aqueous matrix, the pre-atomization temperatures were optimized by a stepwise increase of $100{ }^{\circ} \mathrm{C}\left(\right.$ from $\left.300^{\circ} \mathrm{C}-1200{ }^{\circ} \mathrm{C}\right)$, while keeping the atomization temperature constant at $2000{ }^{\circ} \mathrm{C}$ until optimum absorbance of the analyte was attained. In the aqueous matrix, there was a noticeable reduction in the absorbance of $\mathrm{Cd}$ (34\%) at higher temperatures, indicating a significant loss of analyte, while for $\mathrm{Ag}, \mathrm{Cu}, \mathrm{Cr}, \mathrm{Co}, \mathrm{Fe}, \mathrm{Mn}$, and $\mathrm{Ni}$ the change was insignificant (Table II). This was the optimized pyrolysis temperature which was ascertained for each element. Keeping the pyrolysis temperature constant, the effect of absorbance on increasing the atomization temperature in steps of $100{ }^{\circ} \mathrm{C}$ from $1800{ }^{\circ} \mathrm{C}$ to $2400{ }^{\circ} \mathrm{C}$ was studied.

It was observed that in the $\mathrm{Sb}$ matrix, a higher pre-atomization temperature was required for com-

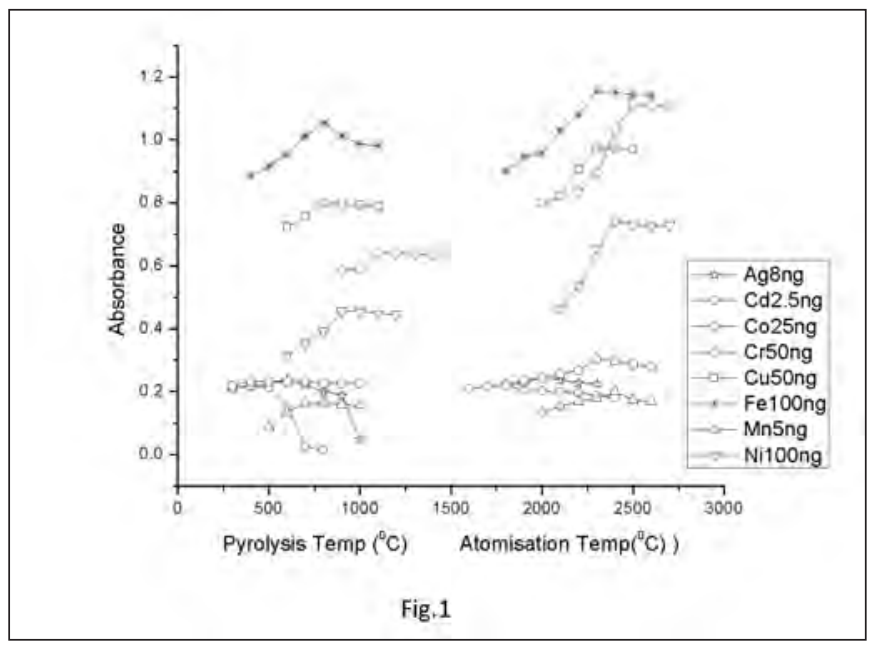

Fig. 1. Plots of the optimization of pyrolysis and atomization temperature.
TABLE II

Effect of Pyrolysis Temperature on Analyte Absorbance

\begin{tabular}{l|lll|ll}
\hline \multirow{2}{*}{$\begin{array}{l}\text { Elements } \\
\left(\mathrm{ng} \mathrm{mL} \mathrm{mL}^{-1}\right)\end{array}$} & \multicolumn{3}{|c|}{ Absorbance* $/$ Aqueous } & \multicolumn{2}{c}{ Absorbance*/Sb } \\
\hline $\mathrm{Ag} /(8)$ & 0.217 & 0.210 & 0.200 & 0.215 & 0.198 \\
$\mathrm{Cd} /(2.5)$ & 0.220 & 0.140 & 0.014 & 0218 & 0.002 \\
$\mathrm{Cr} /(10)$ & 0.232 & 0.233 & 0.232 & 0.232 & 0.230 \\
$\mathrm{Co} /(25)$ & 0.300 & 0.301 & 0.300 & 0.302 & 0.301 \\
$\mathrm{Cu} /(10)$ & 0.160 & 0.162 & 0.162 & 0.158 & 0.161 \\
$\mathrm{Fe} /(10)$ & 0.102 & 0.101 & 0.100 & 0.102 & 0.101 \\
$\mathrm{Mn} /(5)$ & 0.141 & 0.140 & 0.144 & 0.140 & 0.143 \\
$\mathrm{Ni} /(50)$ & 0.371 & 0.370 & 0.372 & 0.372 & 0.370 \\
\hline
\end{tabular}

*Absorbance was of $20 \mu \mathrm{L}$ standard. 
plete decomposition of the matrix and to obtain a matrix-free peak. The increase in pre- atomization temperature caused no loss of analyte or reduction in absorbance for $\mathrm{Ag}, \mathrm{Co}, \mathrm{Cu}, \mathrm{Cr}, \mathrm{Fe}, \mathrm{Mn}$, and $\mathrm{Ni}$. However, in the case of $\mathrm{Cd}$, a large matrix peak was caused due to scattering (Cd $\lambda 228.3 \mathrm{~nm})$ at $400{ }^{\circ} \mathrm{C}$. On increasing the temperature, the background peak decreased; however, there was a loss of Cd causing reduced absorbance (Table III).

Since a higher pre-atomization temperature indicated loss of analyte, the possibility of using lower temperatures and increasing the pre-atomization time was investigated. To ensure complete removal of the matrix the time duration of the pre-atomization step was studied from 5 to 50 seconds. The 50second time duration was sufficient to obtain a matrix-free signal. The effect of atomization temperature on the absorbance of $\mathrm{Cd}$ in the matrix was studied. A constant absorbance was seen from $1800{ }^{\circ} \mathrm{C}$ to $2400{ }^{\circ} \mathrm{C}$. Based on this observation the pre-atomization and atomization temperatures and times duration for $\mathrm{Cd}$ at $228.3 \mathrm{~nm}$ were $400{ }^{\circ} \mathrm{C} / 50 \mathrm{~s}$ and $2000{ }^{\circ} \mathrm{C} / 3 \mathrm{~s}$, respectively.

\section{Chemical Modifiers}

Chemical Modifiers are commonly used to overcome loss of volatile analyte during pyrolysis and many application employing Pd have been reported (21-23). The use of $\mathrm{Pd}$ in $10 \% \mathrm{HNO}_{3}$ for the determination of $\mathrm{Cd}$ in an aqueous and $\mathrm{Sb}$ matrix was also investigated (Table III) for which the optimized pyrolysis and atomization temperatures were $800{ }^{\circ} \mathrm{C}$ and $2000{ }^{\circ} \mathrm{C}$, respectively.

The use of a modifier required the use of higher pyrolysis and atomization temperatures due to the higher vaporization temperature of the Pd-Cd compound which greatly reduced the life of the tube.

TABLE III

Absorbance of Cd With and Without Modifier (Pd)

\begin{tabular}{|c|c|c|c|c|c|c|}
\hline \multirow{2}{*}{$\begin{array}{c}\mathrm{Cd} \\
\left(\mathrm{ng} \mathrm{mL}^{-1}\right) \\
1.25\end{array}$} & \multicolumn{3}{|c|}{$\begin{array}{l}\text { Abs. (Without Modifier) } \\
\text { Pyrolysis Temp. } 400{ }^{\circ} \mathrm{C} \\
\text { Atomization Temp. } 2000{ }^{\circ} \mathrm{C}\end{array}$} & \multicolumn{3}{|c|}{$\begin{array}{l}\text { Abs. (With Pd Modifier) } \\
\text { Pyrolysis temp } 800{ }^{\circ} \mathrm{C} \\
\text { Atomization Temp. } 2000{ }^{\circ} \mathrm{C}\end{array}$} \\
\hline & 0.105 & 0.104 & 0.102 & 0.119 & 0.114 & 0.118 \\
\hline 2.50 & 0.215 & 0.211 & 0.206 & 0.230 & 0.227 & 0.232 \\
\hline
\end{tabular}

TABLE IV

Effect of Sb Concentration on Analyte Absorbance

\begin{tabular}{|c|c|c|c|c|}
\hline \multirow{2}{*}{$\begin{array}{l}\text { Elements } \\
\left(\mathrm{ng} \mathrm{mL}^{-1}\right)\end{array}$} & \multicolumn{4}{|c|}{ Concentration of $\mathrm{Sb}\left(\mathrm{mg} \mathrm{mL}^{-1}\right)$} \\
\hline & 0 & 10 & 20 & 25 \\
\hline \multicolumn{5}{|c|}{ Absorbance* } \\
\hline $\mathrm{Ag} /(8)$ & 0.224 & 0.222 & 0.220 & 0.221 \\
\hline $\mathrm{Cd} /(2.5)$ & 0.220 & 0.211 & 0.209 & 0.216 \\
\hline $\mathrm{Cr} /(10)$ & 0.232 & 0.232 & 0.232 & 0.232 \\
\hline $\mathrm{Co} /(25)$ & 0.300 & 0.302 & 0.301 & 0.302 \\
\hline $\mathrm{Cu} /(10)$ & 0.175 & 0.177 & 0.174 & 0.175 \\
\hline $\mathrm{Fe} /(10)$ & 0.108 & 0.106 & 0.105 & 0.105 \\
\hline $\mathrm{Mn} /(5)$ & 0.162 & 0.166 & 0.162 & 0.164 \\
\hline $\mathrm{Ni} /(50)$ & 0.370 & 0.373 & 0.372 & 0.368 \\
\hline
\end{tabular}

*Absorbance was of $20 \mu \mathrm{L}$ standard.

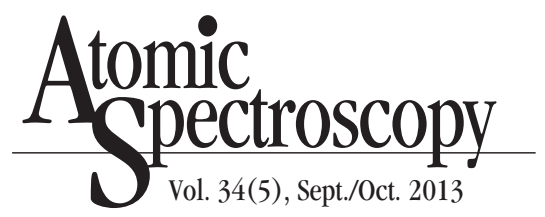

It was observed that the absorbance of Cd increased merely by $10 \%$ (Table III), therefore, the use of a lower temperature and an increased pyrolysis time without modifier was used in the determination of Cd.

\section{Effect of Atomization Temperatures}

The effects of an increase in the atomization temperatures of the analytes $\mathrm{Ag}, \mathrm{Cu}, \mathrm{Co}, \mathrm{Cr}, \mathrm{Mn}, \mathrm{Fe}$, and $\mathrm{Ni}$ in the matrix on the absorbance were also studied. These elements have a high melting point (MP), boiling point (BP), and low volatility; hence, they posed no difficulty in obtaining clean, well separated, quantitative peaks. The sample digest, hydrogen antimony tartarate, decomposes at $200{ }^{\circ} \mathrm{C}$, and antimony chloride has a low boiling point of $220^{\circ} \mathrm{C}$, both of which are completely expelled during the pre-atomization step. Therefore, background absorbance due to scattering of molecular species was not observed. There was no significant difference observed in the absorbance between the aqueous standards and the matrix-matched standards of $\mathrm{Ag}, \mathrm{Cd}, \mathrm{Cu}, \mathrm{Co}, \mathrm{Cr}, \mathrm{Fe}, \mathrm{Mn}$, and $\mathrm{Ni}$.

\section{ETAAS Method for the Direct Analysis of Sb Matrix}

To establish the applicability of an ETAAS method for the direct analysis of an antimony matrix, the effect of varying the concentration of $\mathrm{Sb}$ on a fixed concentration of the analytes was studied under the optimized temperatures. A fixed mid-level concentration of the analyte calibration curve was added to concentrations of antimony ranging from $0-25 \mathrm{mg} \mathrm{mL}^{-1}$. The studies on the matrix effect indicated that under the optimized furnace conditions there was a greater than $90 \%$ recovery of the spiked analyte. It was also observed that varying the concentration of the analyte in $25 \mathrm{mg} \mathrm{mL}^{-1} \mathrm{Sb}$ gave absorbances similar to the aqueous standard (Table IV). 
The calibration curves of the analytes in the absence and in the presence of the matrix were found to completely overlap, which indicated that the matrix did not interfere with the analysis. Hence, the linear calibration mode was employed for the direct determination of these elements. This permitted the determination of $\mathrm{Ag}, \mathrm{Cd}$, $\mathrm{Cu}, \mathrm{Cr}, \mathrm{Co}, \mathrm{Fe}, \mathrm{Mn}$, and Ni employing $25 \mathrm{mg} \mathrm{mL}^{-1} \mathrm{Sb}$ sample substrate. The characteristic concentrations, LOD, and LOQ of the analytes in the aqueous matrix are listed in Table V.

The effect of matrix on the lifetime of the graphite tube was investigated by estimating the stability of the analyte signal after repeated cycles. The lifetime of a given tube was defined as being the period of use up to the point where (a) the sensitivity, compared with the initial level, had decreased by more than $25 \%$ and/or (b) where the overall relative standard deviation (RSD) of the measurements had become five times worse than the initial level (26). The initial RSD signal was around 3-5\% and toward the end, after 200 atomization cycles, became $8 \%$. Figure 2 shows the absorbance signal for $\mathrm{Ni}$ as a function of the atomization cycles. The accumulated matrix did not have any significant effect on analyte absorbance. A similar effect was observed for all other analytes (Ag, Cd, Cr, Cu, Co, Fe, and Mn).

\section{Atomization Mechanism}

The absorbance measured is directly dependent on the number of atoms in the graphite furnace during the atomization stage. It is known that the analyte, which is in nitrate or chloride form, gets converted to the oxide form during the pre-atomization step, and the free atoms are produced in the furnace either due to the carbon reduction of the analyte oxide or the thermal dissociation of the metal oxide. If the Gibb's free energy $\Delta G^{\circ}$ for dissociation is -ve at the appearance temperature, then the carbothermic reduction is the thermodynami-

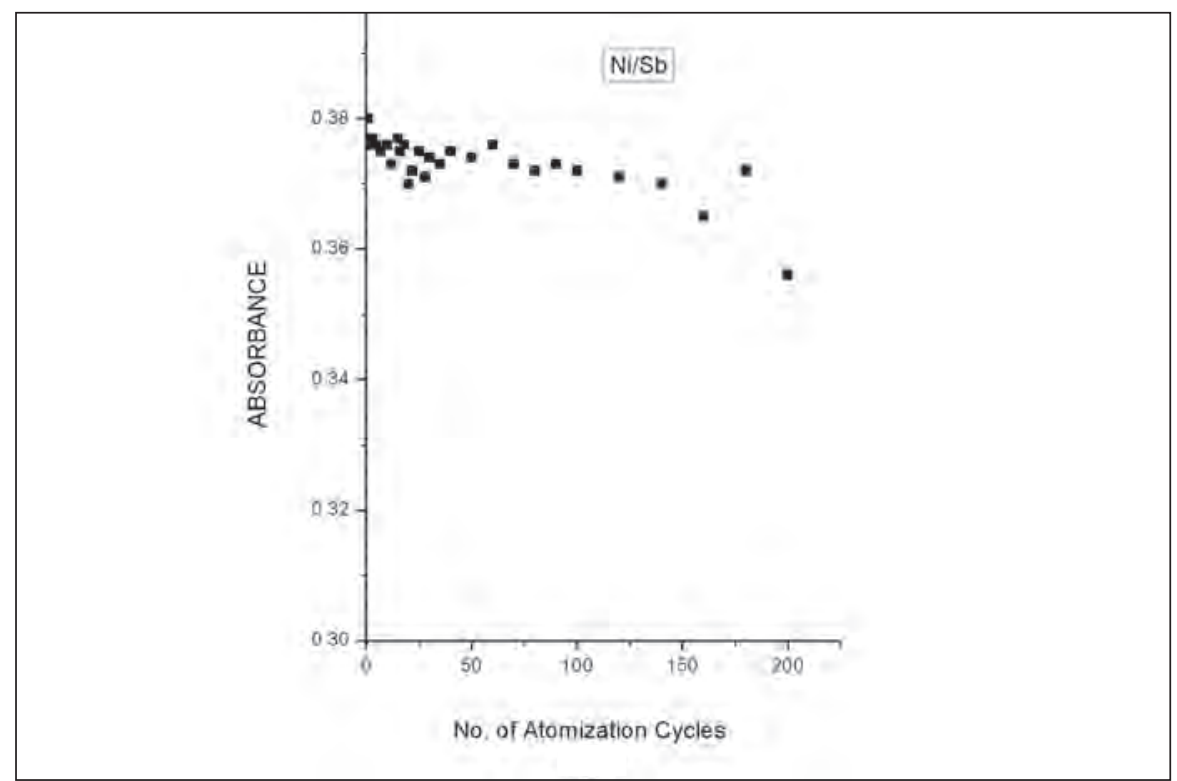

Fig. 2. Absorbance as a function of atomization cycles (Ni). cally favorable mode. However, if the $\Delta G^{\circ}$ is + ve, the oxide dissociation is the probable mode of atom formation (24). The melting and boiling points of the analytes are used to direct and aid in the understanding of the mechanism (27).

To understand the reaction mechanism involved in the atomization, the well-established kineticthermodynamic approach used by Sturgeon et al. was employed (24). The Arrhenius plots of $\ln (\mathrm{A}) \mathrm{vs}$. $\mathrm{T}^{-1}$ of the analytes were obtained and the activation energies $\left(\mathrm{E}_{\mathrm{a}}\right)$ calculated from the slope of the plot.

TABLE V

Analytical Characteristics of the Analytes

\begin{tabular}{lcccccccc}
\hline $\begin{array}{l}\text { Element }(\mathrm{nm}) \\
\text { Anal. Range }\end{array}$ & $\mathrm{Ag}(328.1)$ & $\mathrm{Cd}(228.8)$ & $\mathrm{Co}(240.7)$ & $\mathrm{Cr}(357.9)$ & $\mathrm{Cu}(324.7)$ & $\mathrm{Fe}(248.3)$ & $\mathrm{Mn}(279.5)$ & $\mathrm{Ni}(232.0)$ \\
$\left.(\mu \mathrm{g} \mathrm{mL})^{-1}\right)$ & $0.005-0.020$ & $0.001-0.005$ & $0.005-0.05$ & $0.005-0.02$ & $0.005-0.03$ & $0.005-0.02$ & $0.002-0.01$ & $0.005-0.05$ \\
$\begin{array}{l}\text { Char. Mass (pg) } \\
(\mathrm{Ar})\end{array}$ & 2 & 1 & 4 & 7 & 5 & 8 & 3 & 12 \\
$\mathrm{LOD}\left(\mu \mathrm{g} \mathrm{g}^{-1}\right)$ & 0.02 & 0.01 & 0.06 & 0.2 & 0.14 & 1.3 & 0.07 & 0.2 \\
LOQ $\left(\mu \mathrm{g} \mathrm{g}^{-1}\right)$ & 0.03 & 0.015 & 0.07 & 0.26 & 0.18 & 1.8 & 0.1 & 0.3 \\
Regression & 0.9923 & 0.9985 & 0.9974 & 0.9968 & 0.9956 & 0.9980 & 0.9994 & 0.9958 \\
\hline
\end{tabular}


Signal appearance temperature $\left(T_{\text {app }}\right)$ was measured from the initial portion of the absorption profile. Table VI lists the appearance temperature and activation energy values obtained for $\mathrm{Ag}, \mathrm{Cd}, \mathrm{Co}, \mathrm{Cr}, \mathrm{Cu}$, $\mathrm{Ni}, \mathrm{Fe}$, and $\mathrm{Mn}$ in the aqueous and antimony matrix along with literature reported values.

\section{Aqueous Matrix}

The appearance temperatures of $\mathrm{Ag}, \mathrm{Co}, \mathrm{Cu}, \mathrm{Cr}, \mathrm{Fe}$, and $\mathrm{Ni}$ are much lower than the MPs of their oxides, and the $\Delta G^{\circ}$ value at appearance temperatures is -ve, which indicates that the carbothermic reduction is the favorable atom formation mode. The $\mathrm{E}_{\mathrm{a}}$ values calculated from the Arrhenius plots (Table IV) agreed well when compared with the reported energies. In the case of $\mathrm{Cu}$ and $\mathrm{Co}$, two $\mathrm{E}_{\mathrm{a}}$ values were obtained (Figures $3 \mathrm{a}$ and $3 \mathrm{~b}$ ). The activation energy of $77 \mathrm{kcal} \mathrm{mol}^{-1}$ and $104 \mathrm{kcal} \mathrm{mol}^{-1}$ corresponds to the heat of the atomization of $\mathrm{Cu}$ (s) (MP $1083{ }^{\circ} \mathrm{C}$ ) and Co (s) (MP $\left.1494^{\circ} \mathrm{C}\right)$, respectively, obtained after reduction of the oxide, while the second $\mathrm{E}_{\mathrm{a}} 47 \mathrm{kcal} \mathrm{mol}^{-1}$ and $43 \mathrm{kcal} \mathrm{mol}^{-1}$ corresponded to the bond dissociation energy of $\mathrm{Cu}-\mathrm{Cu}$, Co-Co dimer. The temperature at the intersection of the two lines is around $1224^{\circ} \mathrm{C}$ and $1589^{\circ} \mathrm{C}$, respectively. The existence of $\mathrm{Cu}_{2(\mathrm{~g})}$ and $\mathrm{Co}_{2(\mathrm{~g})}$, is well documented and is said to occur due to increased atom density at the higher temperature. In the case of $\mathrm{Ag}, \mathrm{Co}, \mathrm{Cr}, \mathrm{Fe}$, and $\mathrm{Ni}$, only one activation energy was noted which agrees with the atomization of the individual metal, indicating that the precursor to free atom formation is $M_{(s)}$.

In the case of $\mathrm{Cd}$ and $\mathrm{Mn}$, the free energy change for the carbothermic reaction is -ve at the appearance temperature and the $\mathrm{E}_{\mathrm{a}}$ values of 68 and $98 \mathrm{k} \mathrm{cal} \mathrm{mol}^{-1}$ calculated from the Arrhenius plots and corresponding to the bond dissociation energy of $\mathrm{CdO}$ and $\mathrm{MnO}$, respectively. It was observed that the appearance temperatures of their atoms were lower than the melting points of their oxides. Melting points are attributes of bulk quantities and large cohesive forces and need to be overcome for transformation of atoms from the solid into the vapor phase. However, the extremely low concentration of the analyte oxides in the furnace is presumed to be distributed over a large surface area, probably as a nano-layer (29), which helps to reduce the cohesive forces and enables atom formation at lower temperatures.

\section{Sb Matrix}

The $\mathrm{E}_{\mathrm{a}}$ for $\mathrm{Ag}, \mathrm{Cd}, \mathrm{Cr}, \mathrm{Fe}, \mathrm{Mn}$, and $\mathrm{Ni}$ in the antimony matrix were nearly the same as in the aqueous matrix. However, in the case of $\mathrm{Cu}$ and $\mathrm{Co}$, a single $\mathrm{E}_{\mathrm{a}}$ of $82 \mathrm{k} \mathrm{cal} \mathrm{mol}^{-1}$ and $101 \mathrm{k} \mathrm{cal} \mathrm{mol}^{-1}$ was obtained. It was also observed that the appearance temperatures of $\mathrm{Ag}, \mathrm{Cd}, \mathrm{Co}$,

TABLE VI

$T_{a p p}$ and $E_{a}$ Values and Reaction Mechanism in Aqueous and Sb Matrix

\begin{tabular}{|c|c|c|c|c|c|c|c|c|}
\hline \multirow[t]{2}{*}{$\begin{array}{c}\text { Ele- } \\
\text { ments }\end{array}$} & \multicolumn{3}{|c|}{$\begin{array}{l}\text { Signal Appearance } \\
\text { Temperature (K) }\end{array}$} & \multicolumn{3}{|c|}{$\begin{array}{l}\text { Activation Energy } \\
\text { (kcal/mole) }\end{array}$} & \multirow[t]{2}{*}{$\begin{array}{l}\Delta \mathrm{G}^{\circ} \\
\text { Kcal mole }\end{array}$} & \multirow[t]{2}{*}{$\begin{array}{l}\text { Reaction Mechanism in } \\
\text { Aqueous Solution }\end{array}$} \\
\hline & Aqu..$^{(\mathrm{R})}$ & Aqu. & $\mathrm{Sb}$ & Aqu..$^{(\mathrm{R})}$ & Aqu. & $\mathrm{Sb}$ & & \\
\hline Ag & 1150 & 1170 & 1396 & 67 & 65 & 68 & -2.68 & $\mathrm{Ag}_{2} \mathrm{O}+\mathrm{C}--2 \mathrm{Ag}+\mathrm{CO}$ \\
\hline $\mathrm{Cd}$ & 720 & 865 & 937 & 65 & 68 & 69 & $3_{700}$ & $\begin{array}{l}\mathrm{Ag}_{(\mathrm{s})}-\mathrm{Ag}_{(\mathrm{g})} \\
\mathrm{CdO}_{(\mathrm{s})}-\mathrm{CdO}_{(\mathrm{g})} \\
\mathrm{CdO}_{(\mathrm{g})}-\mathrm{Cd}_{(\mathrm{g})}+0.5 \mathrm{O} 2\end{array}$ \\
\hline Co & 1430 & 1440 & 1892 & $102.4 / 40$ & $104 / 38$ & 101 & $-24_{1400}$ & $\begin{array}{c}\mathrm{CoO}_{(\mathrm{s})}+\mathrm{C}-\mathrm{Co}_{(\mathrm{s})}+\mathrm{CO}, \\
\mathrm{Co}_{(\mathrm{s})}-\mathrm{Co}_{2(\mathrm{~g})}-\mathrm{Co}_{(\mathrm{g})} .\end{array}$ \\
\hline $\mathrm{Cr}$ & 1660 & 1853 & 1863 & 95 & 100 & 102 & $-44_{1300}$ & $\begin{array}{c}\mathrm{CrO}_{(\mathrm{s})}+\mathrm{C}-\mathrm{Cr}_{(\mathrm{s})}+\mathrm{CO} \\
\mathrm{Cr}_{(\mathrm{s})}-\mathrm{Cr}_{2(\mathrm{~g})}-\mathrm{Cr}_{(\mathrm{g})}\end{array}$ \\
\hline $\mathrm{Cu}$ & 1270 & 1343 & 1733 & $77 / 44$ & $79 / 46$ & 82 & $-12_{1700}$ & $\begin{array}{c}\mathrm{CuO}_{(\mathrm{s})}+\mathrm{C}-\mathrm{Cu}_{(\mathrm{s})}+\mathrm{CO}, \\
\mathrm{Cu}_{(\mathrm{s})}-\mathrm{Cu}_{2(\mathrm{~g})}-\mathrm{Cu}_{(\mathrm{g})}\end{array}$ \\
\hline $\mathrm{Fe}$ & 1400 & 1454 & 1628 & 84 & 83 & 83 & $-27_{1500}$ & $\begin{array}{c}\mathrm{FeO}_{(\mathrm{s})}+\mathrm{C}-\mathrm{Fe}_{(\mathrm{s})}+\mathrm{CO} \\
\mathrm{Fe}_{(\mathrm{s})}-\mathrm{Fe}_{2(\mathrm{~g})}-\mathrm{Fe}_{(\mathrm{g})}\end{array}$ \\
\hline Mn & 1480 & 1485 & 1493 & 96 & 98 & 95 & $7_{1500}$ & $\mathrm{MnO}_{(\mathrm{s})}-\mathrm{MnO}_{(\mathrm{g})}$ \\
\hline $\mathrm{Ni}$ & 1590 & 1633 & 1708 & $102.8 / 55.5$ & $98 / 54$ & 99 & $-37_{1600}$ & $\begin{array}{c}\mathrm{NiO}_{(\mathrm{s})}+\mathrm{C}-\mathrm{Ni}_{(\mathrm{s})}+\mathrm{CO}_{(\mathrm{g})} \\
\mathrm{N}_{\mathrm{i}(\mathrm{s})}-\mathrm{Ni}_{2(\mathrm{~g})}-\mathrm{Ni}_{(\mathrm{g})}\end{array}$ \\
\hline
\end{tabular}

The uncertainty of experimental data is $\pm 7-10 \%$.

(R) = reported value (Ref. 24). 


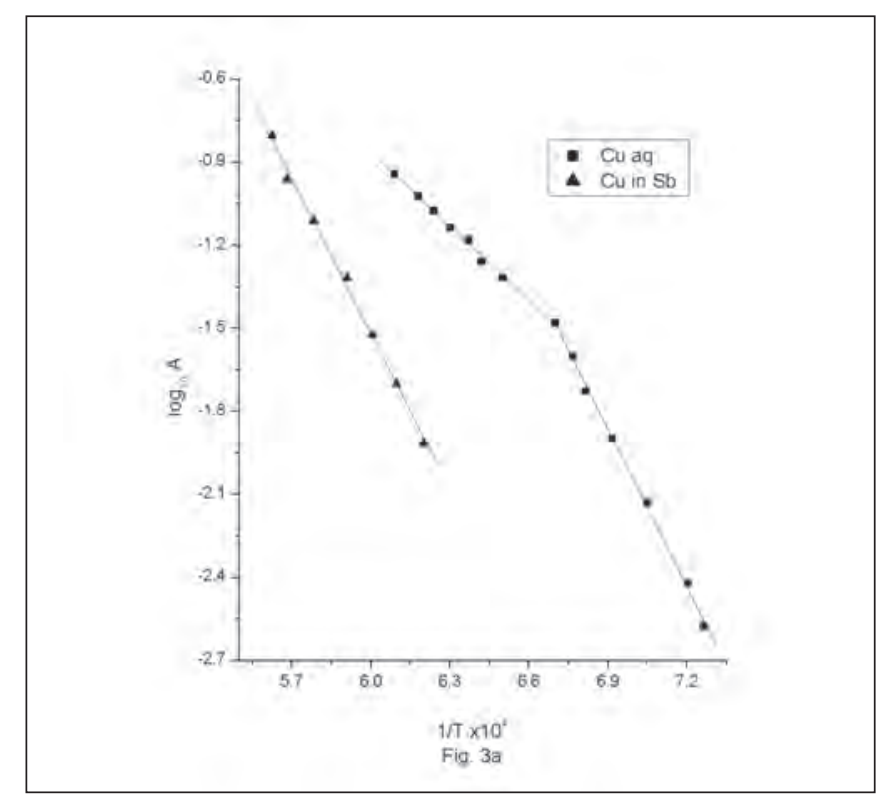

Fig. 3a. Arrbenius plot for Cu in (ם) aqueous and (A) Sb matrix.

$\mathrm{Cu}, \mathrm{Cr}, \mathrm{Fe}$, and $\mathrm{Ni}$ in the $\mathrm{Sb}$ matrix were found to be higher than in the aqueous matrix. The change in atom density was attributed to the increase of oxygen partial pressure in the furnace due to its release (30) by the decomposition of antimony tartarate in the sample digest. It is known to slow down the carbo-thermic reduction as well as the oxidation process. The slow, delayed release of atoms is not favorable for the formation of the dimers; hence, only one $\mathrm{E}_{\mathrm{a}}$ was observed for $\mathrm{Co}$ and $\mathrm{Cu}$.

The $\mathrm{T}_{\mathrm{app}}$ and $\mathrm{E}_{\mathrm{a}}$ were also evaluated for two concentrations of the analytes. It was observed that the signals for $T_{a p p}$ and $E_{a}$ were found to be the same, independent of the matrix and the mass of the analyte atomized. A comparison of the $\mathrm{T}_{\mathrm{app}}$ and $\mathrm{E}_{\mathrm{a}}$ values of this study compared well with those reported in the literature $(24,28)$ and are listed in Table VI. The uncertainty associated with all of the experimental results was between $7 \pm 10 \%$.

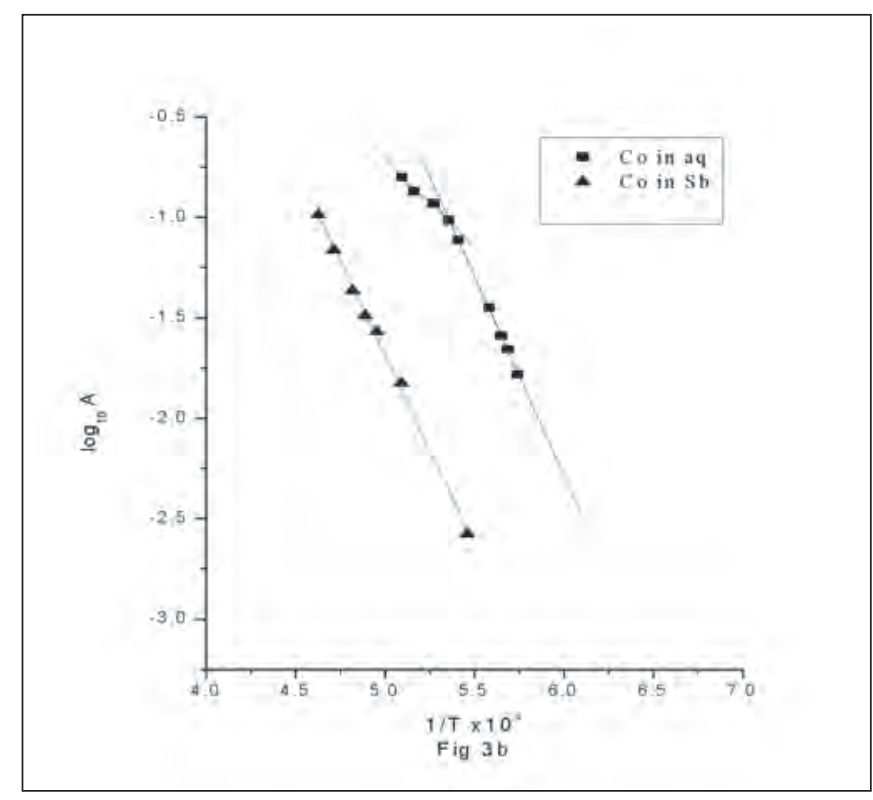

Fig. 3b. Arrbenius plot for Co in (ם) aqueous and (山) Sb matrix.

\section{Recovery Studies}

In the absence of any certified reference material in our laboratory, the recovery of the analytes was established by standard addition and spike recovery of a synthetic sample prepared from high purity antimony. An amount of $0.25 \mathrm{~g}$ of $\mathrm{HP} \mathrm{Sb}$ was processed and made up to $10 \mathrm{~mL}$ volume. The sample spiked with $20 \mathrm{ng}$ to $1000 \mathrm{ng}$ of each analyte was added to the sample and run through the sample preparation procedure. The analytes were quantified using the optimized furnace program. The recoveries of the spikes of the analytes using linear calibration were in the range of 95 to $104 \%$ as shown in Table VII.

\section{Limits of Detection, Limits of Quantification and Characteris- tic Mass}

The limits of detection (LODs) and limits of quantification (LOQs) are estimated from 10 consecutive measurements of the blanks for the individual elements (expressed as $\mathrm{x}+3 \sigma, \mathrm{x}+10 \sigma)$. The blank solutions for non-volatile elements contained
$25 \mathrm{mg} \mathrm{Sb}$ in hydrochloric acid and nitric acid, and 5\% tartaric acid. The characteristic mass, i.e., the mass of the analyte that produces an absorbance of 0.0044 in the presence of the matrix and in aqueous standards, are listed in Table V.

\section{Sample Analysis}

This procedure was applied for the determination of trace elements in samples obtained from the Chemistry Division, BARC, the results of which are summarized in Table VIII. Sb-Ia and Sb-IIa were impure antimony samples obtained from independent sources, which were purified by fractional volatilization and zone refining respectively, to obtain $\mathrm{Sb}-\mathrm{Ib}$ and Sb-IIb. Sb-III was high purity antimony oxide (Johnson \& Mathey, UK).

The results obtained by this method for samples Sb-Ia and Sb-Ib were compared to those obtained by an analyte-matrix separation where the antimony matrix was volatilized as bromide and the residue was taken up for the estimation of analyte impurities. The 


\section{A Amic}

TABLE VII Recovery Studies

\begin{tabular}{cccc}
\hline $\begin{array}{c}\text { Ele- } \\
\text { ment }\end{array}$ & $\begin{array}{c}\text { Added } \\
\left(\text { ng mL }^{-1}\right)\end{array}$ & \multicolumn{2}{c}{ Found } \\
$\left(\right.$ ng mL $\left.^{-1}\right)$ & $\begin{array}{c}\text { Recovery } \\
(\%)\end{array}$ \\
\hline $\mathrm{Ag}$ & 25 & 25.4 & 102 \\
& 50 & 50.2 & 100 \\
$\mathrm{Cd}$ & 2 & 1.9 & 95 \\
& 5 & 5.1 & 102 \\
$\mathrm{Cr}$ & 25 & 25.2 & 101 \\
& 50 & 49.6 & 99 \\
$\mathrm{Co}$ & 50 & 49.8 & 100 \\
& 100 & 102 & 102 \\
$\mathrm{Cu}$ & 25 & 24.8 & 99 \\
& 50 & 50.3 & 101 \\
$\mathrm{Fe}$ & 25 & 25.5 & 102 \\
& 50 & 48.9 & 98 \\
$\mathrm{Mn}$ & 2.5 & 2.6 & 104 \\
& 5 & 4.9 & 98 \\
$\mathrm{Ni}$ & 50 & 48.6 & 97 \\
& 100 & 100.7 & 101 \\
& & &
\end{tabular}

results for $\mathrm{Ag}, \mathrm{Cd}, \mathrm{Cu}, \mathrm{Co}, \mathrm{Cr}, \mathrm{Mn}$, $\mathrm{Ni}$, and $\mathrm{Fe}$ were in good agreement, and the results were in accordance with the Student's $t$ - test for a confidence level of $95 \%$.

\section{CONCLUSION}

A method has been developed for the determination of $\mathrm{Ag}, \mathrm{Cd}$, $\mathrm{Cu}, \mathrm{Co}, \mathrm{Cr}, \mathrm{Fe}, \mathrm{Mn}$, and $\mathrm{Ni}$ in high purity (HP) antimony and antimony oxide. It was found that by optimization of the pyrolysis and atomization temperatures, the effects of the matrix can be reduced and eliminated and the analytes determined in sample digests up to $25 \mathrm{mg} \mathrm{mL}^{-1}$. The $\mathrm{E}_{\mathrm{a}}$ and reactions mechanism of the analytes in aqueous matrix and $\mathrm{Sb}$ matrix were the same. There was no loss of absorbance of the analytes in the Sb matrix; therefore, aqueous standards and a linear calibration were employed. This method, employing in situ matrix volatilization, requires minimum sample preparation, has low detection limits, and is a fast, reliable,

TABLE VIII

Results of Sample Analysis

( $\mathrm{Ia}^{*}$ and $\mathrm{Ib}^{*}$ Values After Bromide Volatilization)

\begin{tabular}{|c|c|c|c|c|c|c|c|}
\hline $\begin{array}{l}\text { Ele- } \\
\text { ment }\end{array}$ & $\begin{array}{c}\text { Sb-Ia } \\
(\mathrm{n}=3) \\
\left(\mu \mathrm{g} \mathrm{g}^{-1}\right)\end{array}$ & $\begin{array}{l}\text { Sb-Ia* }^{*} \\
(\mathrm{n}=2) \\
\left.(\mu \mathrm{g} \mathrm{g})^{-1}\right)\end{array}$ & $\begin{array}{l}\text { Sb-Ib } \\
(\mathrm{n}=3) \\
\left(\mu \mathrm{g} \mathrm{g}^{-1}\right)\end{array}$ & $\begin{array}{r}\text { Sb-Ib* } \\
(\mathrm{n}=3) \\
\left(\mu \mathrm{g} \mathrm{g}^{-1}\right)\end{array}$ & $\begin{array}{r}\text { Sb-IIa } \\
(\mathrm{n}=3) \\
\left(\mu \mathrm{g} \mathrm{g}^{-1}\right)\end{array}$ & $\begin{array}{c}\text { Sb-IIb } \\
(\mathrm{n}=2) \\
\left(\mu \mathrm{g} \mathrm{g}^{-1}\right)\end{array}$ & $\begin{array}{c}\text { Sb-III } \\
(\mathrm{n}=2) \\
\left(\mu \mathrm{g} \mathrm{g} \mathrm{g}^{-1}\right)\end{array}$ \\
\hline Ag & $36 \pm 1.0$ & $37 \pm 0.2$ & $<0.02$ & $<0.02$ & $<0.02$ & $<0.02$ & $<0.02$ \\
\hline $\mathrm{Cd}$ & $<0.01$ & - & $<0.01$ & - & $<0.01$ & $<0.01$ & $<0.01$ \\
\hline Co & $<0.06$ & $<0.06$ & $<0.06$ & $<0.06$ & $<0.06$ & $<0.06$ & $<0.06$ \\
\hline $\mathrm{Cr}$ & $1.0 \pm 0.2$ & $0.96 \pm 0.4$ & $<0.2$ & $<0.2$ & $<0.2$ & $<0.2$ & $<0.2$ \\
\hline $\mathrm{Cu}$ & $104 \pm 2$ & $106 \pm 3$ & $13 \pm 1$ & $12 \pm 2$ & $<0.14$ & $<0.14$ & $<0.14$ \\
\hline $\mathrm{Fe}$ & $35 \pm 1$ & $37 \pm 2$ & $27 \pm 1$ & $28 \pm 2$ & $2.0 \pm 0.1$ & $2.0 \pm 0.1$ & $<1.3$ \\
\hline Mn & $<0.07$ & $<0.07$ & $<0.07$ & $<0.07$ & $<0.07$ & $<0.07$ & $<0.07$ \\
\hline $\mathrm{Ni}$ & $32 \pm 1$ & $30 \pm 2$ & $1.8 \pm 0.1$ & $1.6 \pm 0.3$ & $0.5 \pm 0.2$ & $0.4 \pm 0.1$ & $<0.2$ \\
\hline
\end{tabular}

and accurate means for the determination trace elements (Ag, Cd, Cu, $\mathrm{Co}, \mathrm{Cr}, \mathrm{Fe}, \mathrm{Mn}$, and Ni) in high purity antimony up to $5 \mathrm{~N}$ purity.

\section{ACKNOWLEDGMENT}

The authors are grateful to Dr. Neelam Goyal for scientific discussions during the course of this work.

Received April 18, 2013.

\section{REFERENCES}

1. http://www.webelements.com/ webelements/scholar/elements/anti mony/uses.html.

2. M.V.B. Krishna, D. Karunasagar and J. Arunachalam, Fres. J. Anal. Chem. 363, 353 (1999).

3. Y. Han, H.M. Kingston, R.C. Richter and C. Pirola, Anal. Chem. 73(6), 1106 (2001).

4. J.S. Becker and H.J. Dietz, J. Anal. At. Spectrom. 12, 881 (1997).

5. J.S. Becker, R.S. Soman, T. Becker, V.K. Panday and H.J. Dietze, J. Anal. At. Spectrom. 13, 983 (1998).

6. R. Shekhar, M.V.B. Krishna, J. Arunachalam and S. Gangadharan, At. Spectrosc. 20(1), 25 (1999).

7. S.C. Chaurasia, A.C. Sahayam and R.K. Mishra, Anal. Chem. 74, (23), 6102 (2002).

8. H. Matusiewicz, Spectrosc. Int. 3, 22 (1991).

9. K. Eilola and P. Peramaki, Analyst 128, 194 (2003).

10. A.C. Sahayam, Shiuh-Jen Jiang, and Chia-Ching Wan, Anal. Chim. Acta 598, 214 (2007). 
11. F. Mogi and K. Itoh, Denki Seiko 59, 263 (1988).

12. R.E. Sturgeon, Fresenius J. Anal. Chem. 337, 538 (1990).

13. D. Dobreva, A. Barzev, L. Futekov, and V. Rusev, Fresenius J. Anal. Chem. 328, 557 (1987).

14. A.C. Udas, M.B. Sanglikar, S.A. Kumar, M. Ramanamurthi, M. Sudersanan, and P.K. Mathur, At. Spectrosc. 21(2), 71 (2000).

15. P.J. Purohit, N. Goyal, and S.V. Godbole, At. Spectrosc. 33(3), 92 (2012).

16. K. Dash, S. Thangavel, S.C. Chaurasia and J. Arunachalam, Talanta 70, 602 (2006).

17. P. Barth, J. Hassler, I. Kudrik, and V. Krivan, Spectrochim. Acta Part B 62, 924 (2007).

18. M. Hornung and V. Krivan, Anal. Chem. 70, 3444 (1998).

19. K.Ch. Friese and V. Krivan, Spectrochim. Acta. Part B 53, 1069 (1998).

20. J.C.P. de Mattos, L.F.

Rodrigues, E.M. de Moraes Flores, and V. Krivan, Spectrochim. Acta. Part B 66, 637 (2011).

21. C .Blake and B. Bourqui, At. Spectrosc. 19, 6 (1998).

22. F. Lacoste, G. Van Dalen, and P. Dysseler, Pure and Appl. Chem. 71(2), 361 (1999).

23. D. Weng and G.Q. Zhai, Guang pu 25(4), 567 (2005).

24. R.E. Strugeon, C.L. Chakrabarti, and C. H. Langford, Anal. Chem. 48(12), 1792 (1976).

25. E.B. Sandell and H. Onishi, Photometric Determination of Traces of Metals, General Aspects: Part I, 4th Ed., 1054, (1978).

26. T.C. Dymott, M.P. Wassal, and P.J. Whiteside, Analyst 110, 467 (1985).
27. J. A Dean, Lange's Handbook of Chemistry, McGraw-Hill International Ed., Singapore, ISBN 0-07100189-1.

28. B.V. L'vov, Spectrochim. Acta Part B 52, 1 (1997).

29. B. Smet, Spectrochim. Acta 35 B, 33 (1980).

30. R.E. Strugeon and H.J. Falk, Anal. At. Spectrom. 3, 27 (1988). 